\title{
The "Forgotten Learners". The Plight of Tertiary Learners with an Intellectual Disability: An Opportunity for Provider Partnerships
}

\author{
John R. Grant - General Manager, SkillWise ${ }^{1}$
}

\begin{abstract}
This paper discusses the issue of tertiary education ${ }^{2}$ for adults with intellectual disabilities. It argues there is a dearth of such opportunities, particularly within the mainstream tertiary education system and this limits employment opportunities and social inclusion for adults with intellectual disabilities. This is not consistent with the explicit and implicit commitments from government to tertiary education opportunities for this learner population in both disability and education policy. Therefore, specialist disability support providers and mainstream education providers must work in partnership with employers in order to create more appropriate, inclusive tertiary learning opportunities that will lead to more employment outcomes and ensure greater levels of social inclusion. Moreover, having a range of tertiary education opportunities would not only help to increase employment outcomes in a quantitative sense but would open up a wider range of employment areas.
\end{abstract}

Keywords: Employment, intellectual disabilities, opportunity, tertiary education

\section{Position Paper}

\section{INTRODUCTION}

This paper will argue that the lack of meaningful and inclusive tertiary education (higher education) opportunities for adults with intellectual disabilities is a significant issue with rather serious consequences, including a lack of employment opportunities and social isolation. To begin, there will be a brief glimpse into the limited tertiary education options available for adult learners with intellectual

\footnotetext{
SkillWise is a non-governmental organisation providing training and support for adults with an intellectual disability in Christchurch. All information pertaining to SkillWise has been used with permission from the Board of Trustees.

For the purposes of this paper "tertiary education" is defined as the stage of learning following the completion of a secondary education and as such could include institutions such as polytechnics, industry training organisations, community colleges and universities. The term is synonymous with reference to "higher education" in international literature.
}

disabilities in Christchurch, New Zealand. It will include the experiences of SkillWise with respect to the teaching and learning curriculum offered, and includes examples of collaboration involving a tertiary education provider.

Education and disability policy will be examined in order to illustrate the apparent commitment from government to ensure inclusive tertiary education opportunities for this learner population. There will be a particular focus on the link between education and employment as expressed in key policy documents.

Finally, some thoughts on how to begin addressing this issue are offered, the essence of which relates to establishing partnerships between mainstream tertiary education providers, specialist disability support agencies and employers. The role each stakeholder plays will be discussed to illustrate the distinctive elements, and what could be achieved when these stakeholders work collaboratively.

\section{Examples from the Current Tertiary Environment}

It would appear there are very few meaningful opportunities within the mainstream tertiary education system in Christchurch for adults with intellectual disabilities. However, both Hagley Community College and Christchurch Polytechnic Institute of Technology (CPIT) have acknowledged this issue to some degree, and offer dedicated courses for adult learners with intellectual disabilities. However, it would appear there are very few learners with intellectual disabilities participating in the mainstream curriculum.

In the case of CPIT, the Certificate in Work Skills is offered. This course enables learners to develop skills in literacy and numeracy, and enhance work skills, work readiness, independence skills and enhance personal development (see http://www.cpit.ac.nz). The course modules include: Getting Along at Work; Introduction to Work Options; Money Skills; Planning for Work; Safety at Work; Time Management for Work; Work Presentation, and Work Communication Skills. The aim of CPIT Certificate in Work Skills is 
to ensure the learner is exposed to a wide range of generic work skills and knowledge, and thus provided with a learning opportunity that may lead into a wide range of paid work opportunities.

The CPIT Certificate in Work Skills is delivered in such a way as to recognise the achievement of people who require some support with their learning, either through additional resources, specialised equipment or adapted teaching programmes. The programme emphasises the development of potential and fulfillment of personal goals. People gain general skills that will assist in the workforce as well as some skills specific to individual work aspirations. There is a limited work experience component to the course. This course is exclusively for learners with an intellectual disability.

An example of what can be achieved when a tertiary education provider and a specialist disability provider work collaboratively is illustrated in the working relationship between SkillWise and Hagley Community College. From 2005-2008, SkillWise worked in partnership with, Hagley Community College in the provision of a literacy and numeracy course. This involved teaching basic literacy and numeracy skills through practical everyday exercises and helped to equip people with some of the skills necessary for meaningful social interaction. For the most part, Hagley provided the specialist teaching staff and SkillWise provided the specialist support staff. After 2008, the situation evolved whereby SkillWise supports learners more in the background due to the ability of Hagley to provide the specialist disability support component. However, as with CPIT, this course is segregated from the main curriculum.

\section{Government Policy}

For over ten years, government disability policy in New Zealand has demonstrated a commitment to inclusion and the empowerment of people with disabilities (Grant, 2008). Pathways to Inclusion (Ministry of Social Development, 2001), which builds on aspects of the New Zealand Disability Strategy (Minister for Disability Issues, 2001), sets out a framework for improving the quality of services that assist people to participate in their communities.

The New Zealand Disability Strategy (Minister for Disability Issues, 2001) represents a long-term strategy for changing New Zealand from a disabling to an inclusive society. The strategy has the vision of a society that highly values the lives and continually enhances full participation of disabled people.

This document sets out some very clear objectives designed to facilitate increased participation in the wider community. Central to this is supporting lifestyle choices, education, recreation and culture for people with disabilities. The New Zealand Disability Strategy is also concerned with providing some direction in the creation of opportunities in employment and economic development for people with disabilities.

Recent tertiary education policy has indicated a commitment to providing targeted services which create an inclusive environment for diverse individuals, including students with disabilities (Office of the Minister for Tertiary Education, 2007). Furthermore, the strategy articulates the need to raise the skills and knowledge of the current and future workforce to meet both labour market demand and social needs. One of the most pressing social issues affecting adults with intellectual disabilities is that of social isolation. A more inclusive tertiary education system would provide opportunities to assist in overcoming these barriers, as well as providing a more streamlined pathway into employment.

It is important also to consider the obligations the New Zealand government has made with the ratification of the United Nations Convention on the Rights of Persons with Disabilities (United Nations, 2007). This is a significant international agreement that ensures the rights, dignity and respect of disabled people is acknowledged by government, support agencies and society in general. The purpose of the convention is to promote, protect and ensure the full and equal enjoyment of all human rights and fundamental freedoms by all persons with disabilities. In doing so, the convention interweaves political, civil, economic, social and cultural rights throughout the 50 articles.

Article 24 of the convention sets out a clear direction with respect to tertiary education. This is captured in the following statement:

States Parties shall ensure that persons with disabilities are able to access general tertiary education, vocational training, adult education and lifelong learning without discrimination and on an equal basis with others. To this end, States Parties shall ensure that reasonable accommodation is provided to persons with disabilities.

Whilst there appears to be a commitment to training and education for adults with intellectual disabilities within current government policy, there is little evidence of targeted strategies to implement these policies.

However, one recent initiative, Enabling Good Lives (Minister for Disability Issues, 2011) is intended to go some way in the further implementation of the 
core elements contained within the New Zealand Disability Strategy and The United Nations Convention on the Rights of Persons with Disabilities. This pilot project is intended to effect significant change within both the government funding and contracting environment, together with the service provider sector. Enabling Good Lives is an initiative led by the Office for Disability Issues, and premised on the notion of "everyday life in everyday places" for disabled New Zealanders. This initiative is underpinned by a set of core principles, including self-determination, ordinary life outcomes, community building, whole of life, and mainstream as the default, and will guide the development of the implementation plan. Unfortunately, this pilot does not extend to systemic change within the tertiary education sector in order to create more tertiary learning opportunities for adults with an intellectual disability.

\section{The Need for Tertiary Education and the Role of Experiential Based Learning}

The need for meaningful tertiary education opportunities for adult learners with intellectual disabilities is fairly well-acknowledged in international literature. However, only a small number of studies report full inclusion at post-secondary level (Brown, 2010). This includes a range of options including colleges, technical institutes and universities. For example, Hart, Zimbrich and Parker (2005) comment that a national survey in the United States provided a description of 25 programmes for students with intellectual disabilities on university campuses across the US, however only eight were described as fully-inclusive. One inclusive example would appear to be the Province of Alberta in Canada, where 13 universities, colleges and technical institutes were offering learning opportunities for adults with intellectual disabilities in 2006 (Hughson \& Uditsky, 2007).

There have also been small-scale initiatives in Australia which have focused on the inclusion of learners with an intellectual disability within a university environment (O'Rourke, 2011). Whilst there are positive outcomes associated with these inclusion programmes, it would appear one of the challenges inherent in this process is the inclusion of learners into a system that is not set up to readily accommodate the learner requirements and learning methods of this student population (O'Rourke, 2011). Indeed, such programmes challenge the traditional function of universities which has been providing higher education for the intellectually-elite. For the education experience to be meaningful and have value for the learner, it is important these systemic issues are addressed. It does also raise the question of whether or not universities are the most appropriate place to include learners with an intellectual disability on a wide scale, given the focus of learning typically involves basic communication, social and employment-related skills.

Brown (2010) lists a number of reasons why tertiary education for people with intellectual and developmental disabilities is important;

- people now live and grow up in the community (not in institutions)

- people require further education to reach their potential

- tertiary education needs to take into account variable learning abilities and skills and provide opportunities for individual choices

- adult life requires people to learn different and additional skills to function effectively in the adult world (p. 2).

Experiential-based learning plays an important role in ensuring meaningful and effective teaching and learning opportunities for learners with an intellectual disability. Andresen, Boud and Cohen (2001) outline a number of defining characteristics associated with experiential-based learning, all of which apply to some degree or other to the learning process of adult learners with intellectual disabilities. This includes ensuring the involvement of the whole person - that is intellect, feelings and senses. Active use of the learners' relevant life and learning experiences as a mechanism to maximise understanding is another key component. Continued reflection upon earlier experiences is important in terms of being able to add to and transform learning into deeper understanding, and apply learning in different ways within different contexts. The use of structured activities including simulations, games, role play and visualisations is another key characteristic of effective experiential learning, thus providing the means by which the first step in applying the learning from previous experience can take place.

\section{Teaching and Learning Opportunities within SkillWise}

Currently, ASDAN Towards Independence and Key Steps constitute the main components of the teaching and learning curriculum ${ }^{3}$. ASDAN Towards Independence is an activity-based, no-fail learning scheme where learners can achieve at their individual level. It is a personal development programme that provides a framework of activities designed to develop personal, social and work-related skills, and promote independence and social inclusion. Towards Independence covers six key areas:

\footnotetext{
${ }^{3}$ For more information regarding ASDAN visit www.asdan.co.nz
} 
1. Creative Studies - this includes modules such as Performing Arts, Pottery \& Ceramics, and Photography \& Multimedia.

2. Cultural - this includes modules such as Current Affairs, Popular Culture, The World Around Us and Environment.

3. Independent Living Skills - this includes modules such as Meal Preparation, Money, Using Transport, and Working Towards Self-Sufficiency.

4. Leisure/Recreation/Sport - this includes modules such as Sports Studies, Water Skills, Animal Care and Yogacise.

5. Personal Development/Citizenship - this includes modules such as Knowing About Myself, Coping with People, Relationships, Self Advocacy and Out in the Community.

6. Work Related - this includes modules such as Vocational Training/Experience, Horticulture, Moving on from School, World of Work, and Work Awareness.

There are six levels of support within Towards Independence. This ranges from "no help" - where a person can do things on their own, through to "experience recorded": where a person is provided with an experience of an activity but is unable to take part. This ensures a wide range of participants and means of collecting learner experiences and achievements.

Key Steps provides a next-step in the learning process and is more indicative of a tertiary education opportunity. Key Steps is a comprehensive programme of activities in a range of topic areas covering Citizenship, Community, Values, Health, Environmental Education, Personal Finance, Identity, Enterprise, and Internationalism. They are presented in the form of personal challenges and encourage students to develop their personal skills and take responsibility for their own learning. Students must complete 30-35 hours of challenges to achieve each certificate. Evidence of all the personal challenges completed are collated in a portfolio of evidence, along with the award book and recording documents (Action Plans, Reviews and Summaries of Skills Achievements). Completion of the Key Steps Award can count as two of the six credits needed to achieve the Bronze Award or two of the 12 credits needed to achieve the Silver/Gold Award or the Certificate of Personal Effectiveness qualification.

\section{DISCUSSION}

Clearly, there is a correlation between tertiary training and education and employment outcomes. Put simply, this relates to increasing employability through tertiary education. This idea is firmly embedded in thinking associated with career development for non-disabled people, however, it appears to be somewhat absent in respect of career development for adults with an intellectual disability.

The challenge for SkillWise learners (and adults with intellectual disabilities generally) is to find meaningful tertiary education opportunities beyond the traditional vocational training service provision environment. This environment has historically operated in somewhat segregated fashion and has not sought to establish meaningful partnerships to any great degree. Invariably, tertiary education opportunities within this context are limited.

\section{Government Policy}

Changes in thinking - reinforced through government policy including the New Zealand Disability Strategy (Minister for Disability Issues, 2001), Pathways to Inclusion (Ministry of Social Development, 2001) and The United Nations Convention on the Rights of Persons with Disabilities (United Nations, 2007) - have given impetus to redefining the way in which disabled people are supported. Community Participation, an approach to disability support developed through Pathways to Inclusion, is indicative of the paradigm shift that has seen a move away from more traditional models of support based largely on a segregated approach, towards an integrated and inclusive approach (Grant, 2008).

Enabling Good Lives (Minister for Disability Issues, 2011) will undoubtedly shape future government policy, contracting arrangements and funding systems. Moving away from bulk funding services and instead providing funding to the individual is a core component of the systems transformation advocated for in the report. In terms of disability, provider transformation Enabling Good Lives will provide for far-reaching change in the sector. Indeed, the nature and scale of change intended with this initiative has not been seen in New Zealand since the deinstitutionalisation process of the 1990s through to the early 2000s. Providers will be expected to organise services to clearly align with the guiding principles. In essence, this will require a move away from the prevailing paradigm of a somewhat segregated centrebased approach to a community-inclusive approach based on facilitation-based support.

\section{The Role of Disability Providers}

An approach to support utilising brokerage or facilitation has been gaining greater recognition over the last five to ten years (Grant, 2007). Such an approach involves supporting people to access community-based activities and opportunities, 
including mainstream leisure and recreation activities, together with employment and of course tertiary education opportunities where they exist (Grant, 2007). This requires disability-support organisations to reinvent themselves in ways that embrace partnerships with organisations outside the disability sector (Grant, 2008). Ultimately, this helps people in achieving higher levels of independence (from direct support) and self-determination through such things as gaining paid employment and forming new friendships, including non-disabled people (Grant, 2007). A facilitation-based approach to support requires a significant paradigm shift in terms of how support is conceived, organised and provided. It is based on the notion of "being of service" and has the person at the centre of planning and decision-making processes.

\section{The Role of Tertiary Education}

Generally-speaking, tertiary learning opportunities for adults with intellectual disabilities encompass three broad areas:

- Social and adaptive skills

- Leisure and recreation

- Employment.

Social and adaptive skills constitute the most basic of education required for many adults with intellectual and development disabilities (Brown, 2010). Much of the skill-development in this area is targeted towards equipping people with skills necessary to live a meaningful life in the community. This includes, but is not limited to, personal hygiene, cooking, basic money management and developing a range of relationships (Brown, 2010).

Leisure and recreation pursuits are generally viewed as important aspects of lifestyle for people with intellectual disabilities and indeed, nondisabled people (Brown, 2010). One of the valuable advantages of such activities is that they can take place in community facilities and be of an inclusive nature (Brown, 2010). There is evidence to suggest that not only are there health benefits from participation in leisure and recreation activities but also other outcomes such as improved memory, cognitive ability and motor skills (Brown, 2010). All such activities can, and often do, involve training and education which enhances abilities, health, and social communication, thus positively influencing a wide range of human activities (motivation, self-image, friendship, travel skills, and so on) (Brown, 2010). Therefore, not only are these activities enjoyable, but they also provide a learning experience whereby transferable skills and attributes can develop.
A focus on employment-outcomes must increase in respect of training and education for adults with intellectual disabilities and one should not underestimate the cumulative effect of education. The skills and knowledge gained in training and education relating to social, adaptive and recreation skills can transfer into the employment realm. Indeed, social skills are now recognised as a key component in the successful development of employment (Brown, 2010).

In terms of courses that currently exist, almost without exception they are overly generic in nature (focusing on getting ready for work, time management, getting along at work, health and safety and so on) and too long (generally two years). Whilst the aforementioned areas are important, the primary focus must be on equipping people with the specific skills required for a range of different job areas within the labour market. Moreover, under the right circumstances, the courses may in fact assist employers to rethink and reorganise some of the roles within their companies or organisations.

\section{RECOMMENDATIONS}

First and foremost, a greater commitment to the career development of adults with an intellectual disability requires a collaborative approach. This would involve a tertiary education provider, a specialist disability support agency, and of course, an employer - each with a distinct role. The primary aim would be to provide targeted courses to equip people with the knowledge, skills and experience to gain work within a specific job area. This would be achieved through an approach based on experiential learning principles and a work-based training model. Ideally, such a course would fit within the structure of an existing course. One of the aims should be to increase the range of employment areas beyond those typically associated with adults with an intellectual disability, for example, collecting trolleys in a supermarket.

It is important to ensure the education responsibilities reside with a mainstream education provider in the first instance as this will guarantee a more inclusive approach as per key government policy documents. The role of the tertiary education provider in the first instance would be to create opportunities, where possible, within the existing curriculum. This would inevitably involve adapting courses to embrace an experiential-based learning approach, rather than a more traditional classroom-based model. With an approach based largely on experiential learning, it is more likely that the learning outcomes will be more productive and add more value for learners with intellectual impairment. The primary reason for this is due to the learning being grounded in actual 
experience and not based on having to attempt to understand largely abstract concepts.

In terms of some of the specific functions which would be the responsibility of the tertiary provider, this would incorporate all the elements of any tertiary course, including such things as providing learning resources, maintaining learning standards, and various learner administration tasks. In terms of learner resources, this would include classroom space (which may only involve one part day per week), teaching staff, and learning resources (incorporating hard copy material and electronic material). As far as maintaining learner standards and administration, this would incorporate recording learner progress and providing support where required, as well as other sundry administration.

As far as learning resources are concerned, these need to embrace 21 st century technology, in particular, the use of information technology incorporating both software and hardware. From a software perspective this could incorporate a number of different visual learning resources. For example, within the context of a gardening and horticulture course there could be a range of short videos demonstrating such tasks as planting, weeding, spraying and so on. Furthermore, these videos could incorporate footage of the learners themselves. This would provide a useful resource to refer back to when the person is involved in work experience or indeed a paid role. The ideal platform for this would be an ipad or tablet device, and would be a key resource both for the course itself and on-going learning beyond the course.

The disability support provider would play an important role in several different ways. Key focal areas could incorporate assistance with relationship development, skill development, problem solving, encouragement, and ongoing support for the person when in employment. Furthermore, the disability provider could liaise between the education provider and the employer on an as-required basis, to assist the learning process and resolve issues as, and when, required. Also, support providers could assist in the development of the skills and competencies required to use an ipad or tablet device.

Clearly, the employer plays a crucial role in providing work experience and ultimately on-going paid work. The work experience component of this approach to teaching and learning forms a critical element as it would form the basis of the learning experience. Moreover, there should be a clear expectation the work experience would translate into a paid job once the course is completed if the learner achieved the required standard.

Through a collaborative approach with the education provider and the disability support provider, the employer would be well-resourced to ensure the learning and support requirements of the individual are met in a relatively seamless fashion. This, in turn, would enable the employer to focus on the work experience and thus maximise the practical learning experience.

\section{CONCLUSION}

It is time to ensure far more value is placed on tertiary education for adults with intellectual disabilities. This will assist in increasing employment outcomes and social inclusion for adults with an intellectual disability. There is clear evidence within government disability and education policy of the intent for education opportunities for disabled people to be more available and inclusive. However, in spite of the state investing significant resource in the primary and secondary education systems, there continues to be very little investment in the tertiary education sector for meaningful learning opportunities for adults with intellectual disabilities.

This paper has argued the way forward should be based around a collaborative approach involving a disability provider, a tertiary education provider, and an employer. Each of these stakeholders would play a distinct role, based on the principle of social inclusion. Ultimately, this would enhance the tertiary education experience for adults with intellectual disabilities and provide a range of learning options that would lead to increased employment outcomes.

\section{REFERENCES}

Andresen, L., Boud, D. \& Cohen, R., (2001). Experience-based learning: Contemporary issues. In G. Foley (Ed.), Understanding adult education and training (pp. 225-239). (2nd ed.). Sydney: Allen \& Unwin.

Brown, R. I. (2010). Adult education and intellectual and allied developmental disabilities. Buffalo, NY: Center for International Rehabilitation, Research, Information and Exchange.

Grant, J. R. (2007). Community participation and quality of life for ex-Templeton Centre residents: Policy, theory and practice: An opportunity for NGO collaboration. Journal of Social Policy New Zealand, 30, 79-93. 
Grant, J. R. (2008). Paid work - A valued social role that is empowering more people with an intellectual disability and providing employers with dedicated employees! Journal of Intellectual and Developmental Disability, 33(1), 95-97.

Hart, D., Zimbrich, K., \& Parker, D. R. (2005). Dual enrollment as a postsecondary education option for students with intellectual disabilities. In E. E. Getzel \& P. Wehman (Eds.), Going to college: Expanding opportunities for people with disabilities (pp. 253-270). Richmond, VA: Paul H. Brookes.

Hughson, E., \& Uditsky, B. (2007). Inclusive postsecondary (tertiary) education for adults with Down syndrome and other developmental disabilities: A promising path to an inclusive life. Portsmouth, UK: Down Syndrome Educational Trust.

Minister for Disability Issues (2001). The New Zealand disability strategy: Making a world of difference. Wellington, New Zealand: Ministry of Health.

Minister for Disability Issues (2011). Enabling good lives - A report to the Minister for disability issues. Retrieved from www.odi.govt.nz

Ministry of Social Development (2001). Pathways to inclusion. Wellington, New Zealand: Ministry of Social Development.

Office of the Minister for Tertiary Education (2007). Tertiary education strategy 2007-12. Wellington, New Zealand: Ministry of Education.

O'Rourke, J. (2011). Inclusion at university: Can we do more to open the door? Journal of Social Inclusion, 2(2), 19-33.

United Nations (2007). Convention on the rights of persons with disabilities. Retrieved from http://www.un.org/disabilities/convention/ conventionfull.shtml

\section{AUTHOR PROFILE}

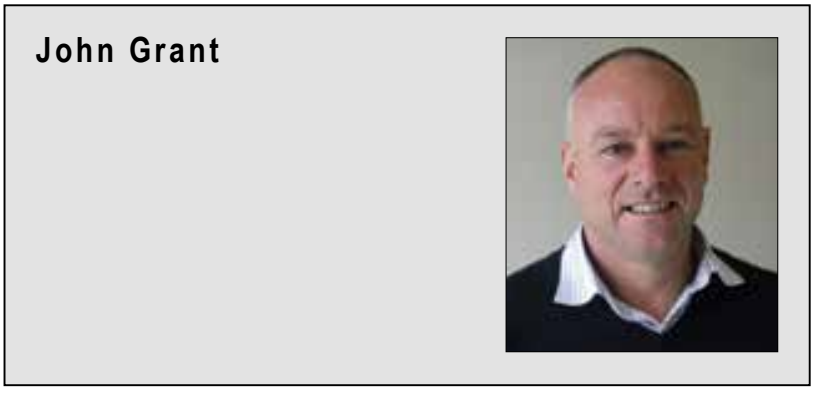

John Grant is the General Manager at SkillWise, a nongovernment organisation providing a range of support and training options for adults with an intellectual disability to assist in facilitating social inclusion in a variety of ways, including through employment. He has held other roles in the disability sector including Chair of Inclusive NZ (formerly the New Zealand Federation of Vocational and Support Services), an umbrella organisation of disability providers, since 2009. He also sits on several government advisory groups including the Enabling Good Lives Advisory Group in Christchurch. This a demonstration trialling new ways of supporting young disabled people post-secondary school, including individualised funding. He held a parttime lecturing position at the Christchurch Polytechnic Institute of Technology, teaching disability theory, policy and support practices from 2008 until 2012, and he continues to chair the Human Services Advisory Committee. John has authored several papers looking at disability theory, policy and support practices, with a particular focus on quality of life and collaboration. He graduated from the University of Canterbury in 2002 with a Master of Arts in Sociology, having completed a thesis looking at quality of life issues for adults with an intellectual disability who had been through a deinstitutionalisation process.

\section{Email:}

john.grant@skillwise.org.nz 